\title{
Fatigue life test of reinforced grinding bearings
}

\author{
Zhuan Zhao ${ }^{1,2}$,Xiaochu Liu ${ }^{1,2, ~ *}$,Zhe Qin ${ }^{1,2}$, Youcheng Chen ${ }^{1,2}$ \\ 1Department of Mechannical and Electrical Engineering, Guangzhou University, Guangzhou 510006, China \\ 2.Key Laboratory of high-peformance Metal Materials Reinforced Grinding Machining, Guangzhou University, Guangzhou \\ 510006, China
}

Abstract: There are 4 groups of car wheel bearings, in which the inner ring of the 2 groups of bearings were reinforced by grinding process while the other 2 groups of bearings were not. After finishing grinding, then following by superfinishing to make them fit with steel and cage. When it was completed, 4 groups of bearings on the bearing fatigue testing machine were able to test the change of surface quality, operation temperature, vibration and clearance. The result shows that the surface quality, operating temperature, vibration and clearance changes of bearings are better than those untreated after reinforced grinding.

\section{Introduction}

Bearing is an important and basic component, which is widely used in military and civilian areas. With the implementation of 2015 China's manufacturing, intelligent, automation of mechanized equipment improve continuously, a new challenge about the strength, reliability and fatigue life of the bearing is emerging. In terms of fatigue life of bearings, many scholars have done a lot of researches. P.C. Bastias, S.T. Hadfield $[1,2]$ et al believe that the fatigue failure of the bearing is divided into two stages. The first stage is the plastic deformation of the material, and cracks are formed in the plastic deformation zone. This stage is relatively short, accounting for about $10 \%$ of the damage process, but it creates the condition for the formation, expansion and spalling of crack in the second stage. Therefore, the plastic deformation of metal is the precondition of crack generation. G.R. Miller [3] et al studies and suggests that rolling contact fatigue is mainly in two forms: initial rolling contact fatigue of the *Corresponding author:XiaoChu Liu.gdliuxiaochu@163.com subsurface and of the near-surface. Li Xunjiao [4] et al thinks that the rolling bearing contact fatigue is under the action of alternating cyclic contact stress, local permanent cumulative damage is occurred on the contact surface and experienced the process of crack generation , expansion, and resulted in small pieces or small pieces of metal peeling. Wanchang Sen and G.. John $[5,6]$ at al introduce that under the condition of normal use, the materials of bearing surface are subjected to repeated action of high contact stress, crack initiation on the surface or subsurface, and ultimately lead to fatigue failure of rolling bearings.

This paper will make a fatigue life test on reinforced grinding bears and untreated bearings. The reliability and feasibility of reinforced grinding process are revealed by comparing different aspects. It is beneficial to improve the fatigue life of bearings.

\section{Reinforced grinding experiments}




\subsection{The principle of reinforced grinding}

Reinforced grinding is a processing method based on composite fatigue resistance, corrosion resistance and wear precision machining technology of metal materials. This kind of processing technology can help obtain bearing ring with residual stress. The principle is shown in Figure 1 and 2. We fused strengthened abrasive material with high pressured gas and used injection system to produce mixed high-pressure gas liquid solid three-phase jet flow. As the collision of ring surface happened randomly ${ }^{[1]}$, thereby grinding on the workpiece surface was strengthened.

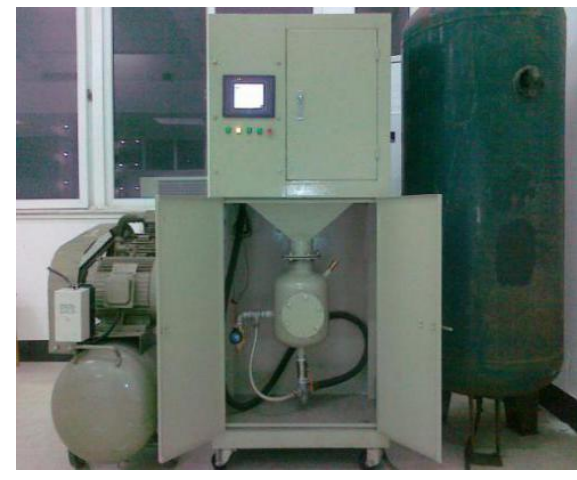

Figure 1. Reinforced grinding machine

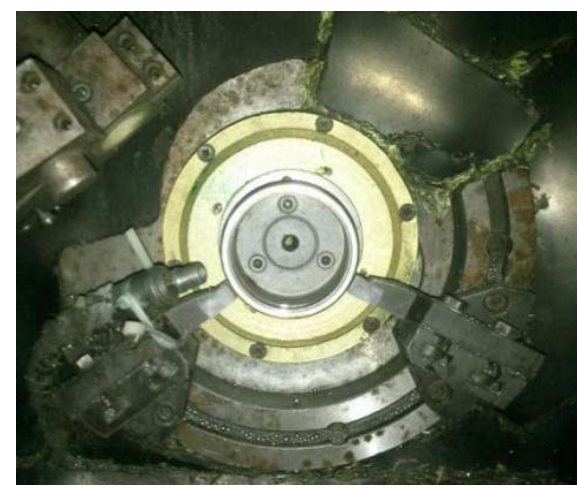

Figure 2. Electromagnetic centerless fixture

\subsection{Experimental sample}

We selected 4 groups of bearings and numbered them as 1 4, the inner ring of the No.1 and No.2 bearings were reinforced by grinding process while the other 2 groups of bearings were not. The bearing sample was automobile hub bearing with model DAC34640037B, the sample was removed from the production line after grinding the bearings (no super fine), the main size was shown in Table 1. The bearing was a double row angular contact ball bearing. The inner and outer ring physical map is shown in figure 3 .
Table 1. Main dimensions of DAC34640037B

\begin{tabular}{lcccccc}
\hline $\begin{array}{c}\text { Bearing } \\
\text { code }\end{array}$ & d & D & B & C & $\begin{array}{c}\text { Seal } \\
\text { up }\end{array}$ & $\begin{array}{c}\text { Net } \\
\text { weight }\end{array}$ \\
$\begin{array}{l}\text { DAC3464 } \\
\text { 0037B }\end{array}$ & 34 & 64 & 37 & 37 & B & $0.43 \mathrm{~kg}$ \\
\hline
\end{tabular}

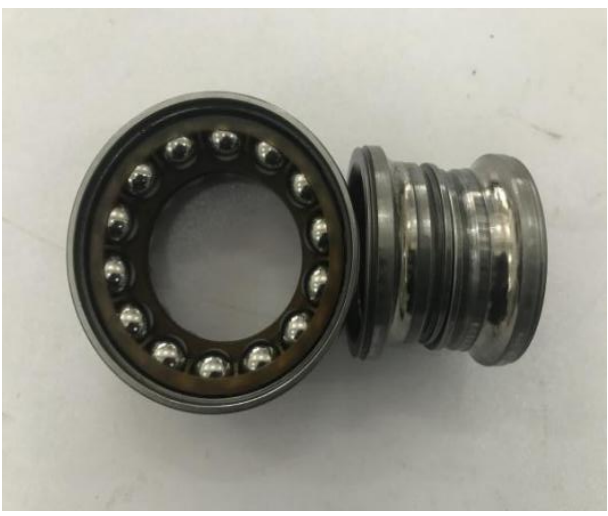

Figure 3.Inner and outer rings

\subsection{Process parameters of Reinforced grinding}

The process parameters are set up and then processed, process parameters are shown in table2 and table3.

Table 2. compounding proportion

of abrasive materials

\begin{tabular}{|c|c|}
\hline Bearing steel ball with diameter of $2 \mathrm{~mm}$ & 1400gram \\
\hline Abrasive powder (Brown corundum) & 400gram \\
\hline Triethanolamine solution & 600 gram \\
\hline 30 pecent of AES solution & 200gram \\
\hline Water & 400gram \\
\hline \multicolumn{2}{|l|}{ Table 3.other process parameters } \\
\hline diameter of nozzle $(\mathrm{mm})$ & 10 \\
\hline Jet angle $\left(^{\circ}\right)$ & 45 \\
\hline Processing time $(\mathrm{min})$ & 3 \\
\hline Workpiece speed $(r / m i n)$ & 100 \\
\hline Jet pressure（Mpa） & 0.6 \\
\hline
\end{tabular}

\section{Rolling contact fatigue life test}

After grinding, the raceway surface of 4 groups of bearings is machined to superfinish. The processing capacity is $10 \mu \mathrm{m}$ after superfinish. The No.1 and No.2 bearing are loaded with steel ball and cage, so that they can be assembled completely and keep good lubricity, and put into the bearing fatigue test machine bearings, which is shown in Figure 4. Because the bearings are 
automotive wheel hub bearings, therefore they require simulation of vehicles in general driving conditions. Each bearing runs 65 hours, the speed is $999 \mathrm{r} / \mathrm{min}$, the radial load is $8 \mathrm{kN}$, the test machine will record the running condition of the bearing every $10 \mathrm{~s}$, including the temperature, vibration and clearance of bearings.

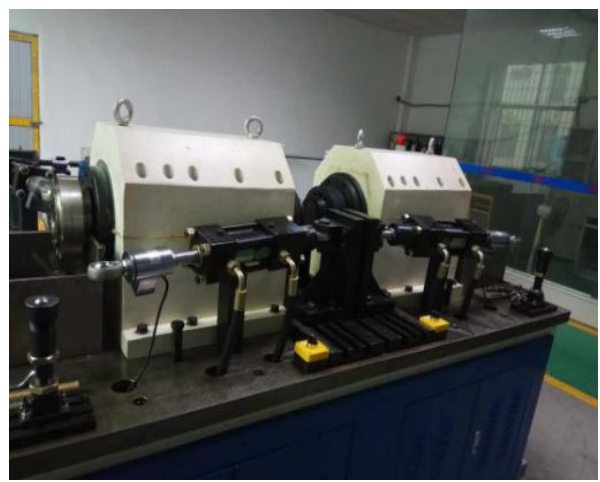

a

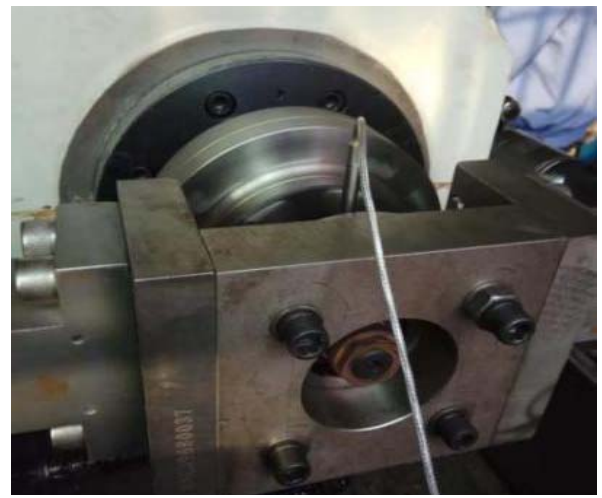

b

Figure 4. Bearing fatigue life testing machine

\section{Results analysis}

Figure 5 and 6 show the conditions of inner ring after finishing test. Comparing the surface of the bearing inner raceway with the reinforced grinding process or without the process, it can be seen that after running through the $65 \mathrm{~h}$ load, the bearing rings surface that after grinding were still bright, while the untreated bearing rings surface began to become yellow and purple because of the high temperature. So the bearing's running temperature is closely related to the force, clearance, vibration of bearings.

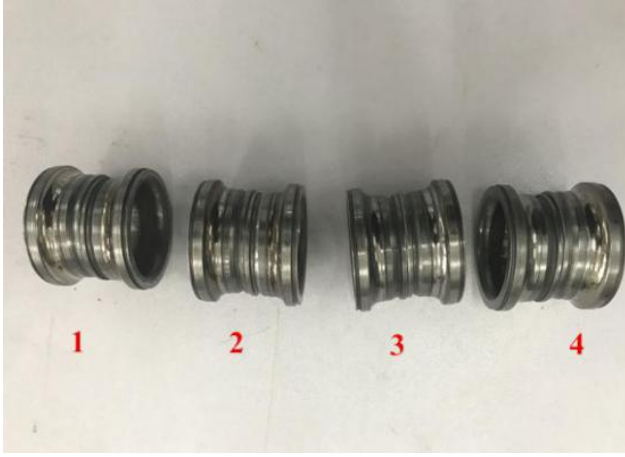

Figure5. Bearing inner ring after test

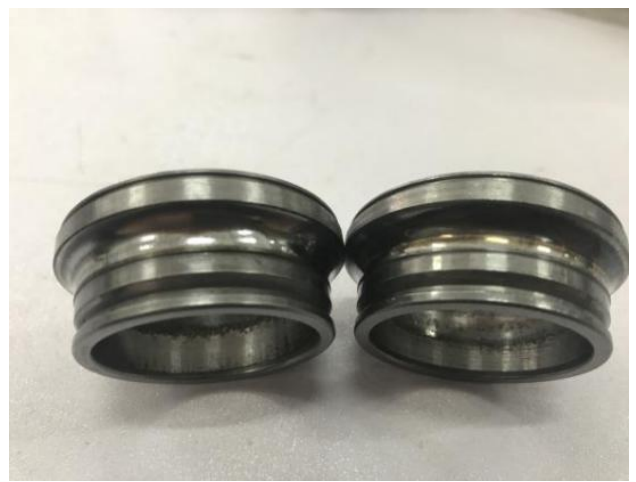

Figure 6. No. 2 and No. 3

Figure 7 shows the variation of the temperature of bearings along with time during the test. In the first 3 hours, the temperature of the 4 sets of bearings increased sharply to about $87^{\circ} \mathrm{C}$. After that, the temperature remained between $85 \sim 90^{\circ} \mathrm{C}$. Within 35 hours of the test, the No.1 and No.2 bearing were almost the same temperature relative to the other 2 groups, but after 35 hours, the temperature of No.1 and No.2 bearing was significantly lower than No.3 and NO.4. It is precisely because of high temperature, the No.3 and No.4 bearings become yellow, purple as a result. Figure 8 shows the variation of vibration of bearings with time during the test. The vibration of the bearing is closely related to the lubrication characteristics and processing quality of the surface during operation.

The standard deviations of the 4 groups of bearings were: $\sigma_{1}=0.07630, \sigma_{2}=0.07633, \sigma_{3}=0.1000$, $\sigma_{4}=0.15426$

The standard deviation of No.1 and No.2 bearing is smaller than No.3 and No.4 bearing, which indicates that the stability of No.1 and No.2 bearing is better than No.3 and No.4. 


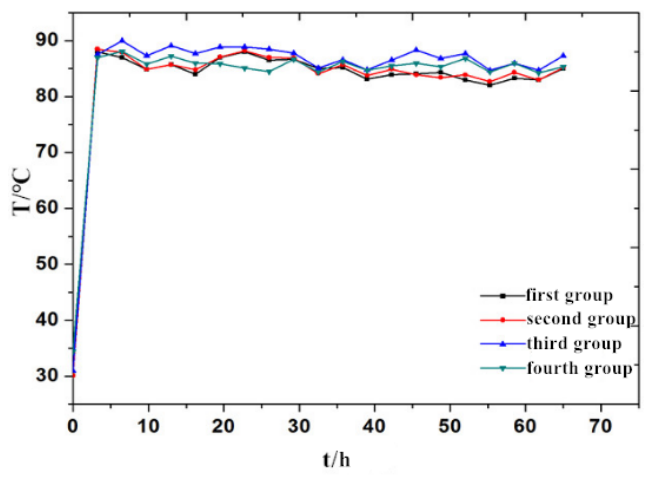

Figure6. Bearing temperature variation

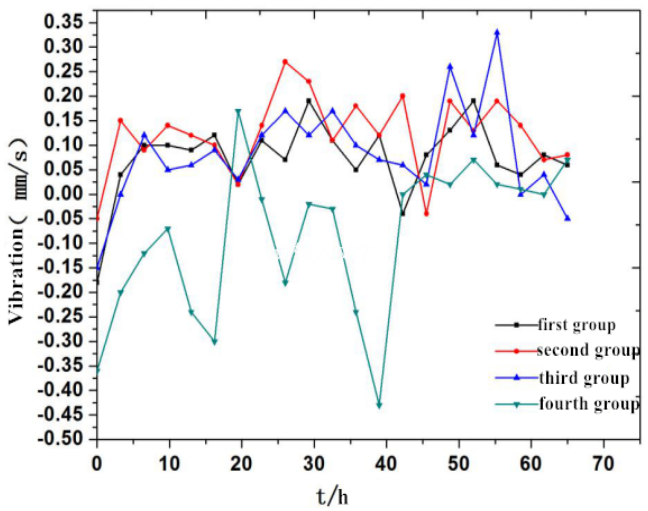

Figure 7. Bearing vibration change

Figure 9 shows the clearance change of bearings with time during the test. The clearance change range of No.1 and No.2 bearing was obviously smaller than No.3 and No.4. No.4 bearing had the biggest change of clearance. It also confirms that No.4 bearing has the worst running stability. It also shows that the temperature and vibration performance of the latter two groups are lower than those of the first two groups.

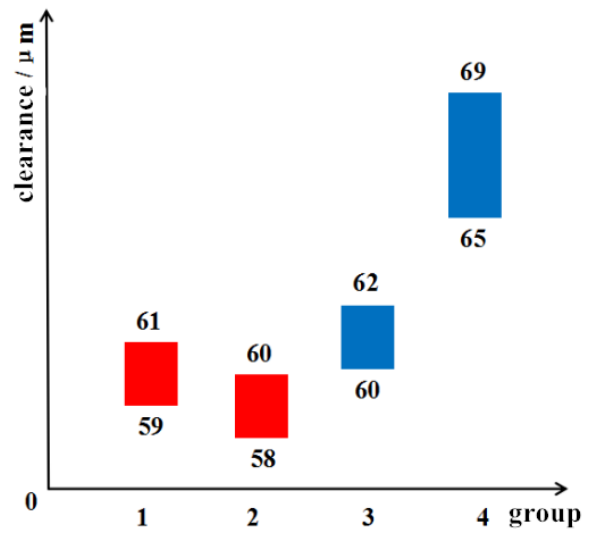

Figure 9.Bearing clearance variation

\section{Conclusion}

(1) The bearing will be yellow and purple after running for a certain period of time under the load. If the bearing raceway is subjected to reinforce grinding, this will improve the situation, at least the deterioration time of raceway surface will be prolonged

(2) Compared with the bearings without the raceway surface treatment, the bearings with reinforced grinding had better running temperature, stability and clearance change.

\section{References}

1. Bastias P C, Hahn G T, Rubin C A, V Gupta,X Leng. Wear, 171,(1994),169-178.

2. Hadfield M, Tobe S, Stolarski T A. Tribolog Internaational, 27,(1994),359-367.

3. Miller G R, Keer L M, Cheng H S. Proceedings of the Royal Society A,397,(1985),197-209.

4. Eryu Shao, Xunjiao Li. Journal of Henan University of Science and Technology(Natural Science),1,(198 6),51-60.(In Chinese)

5. Changsen Wan. Method of analysis of rollingbearings. (China Machine Press, 1987). (In Chinese)

6. Eleftherakis J G,Shelton D C.Lubrication Engineering, 51,(1995), 205-208. 